University of Vermont

UVM ScholarWorks

Rubenstein School of Environment and Natural Rubenstein School of Environment and Natural Resources Faculty Publications

$1-1-2015$

\title{
Are conservation organizations configured for effective adaptation to global change?
}

\author{
Paul R. Armsworth \\ The University of Tennessee, Knoxville \\ Eric R. Larson \\ The University of Tennessee, Knoxville \\ Stephen T. Jackson \\ United States Geological Survey \\ Dov F. Sax \\ Brown University \\ Paul Simonin \\ Cornell University
}

See next page for additional authors

Follow this and additional works at: https://scholarworks.uvm.edu/rsfac

Part of the Climate Commons, Community Health Commons, Human Ecology Commons, Nature and Society Relations Commons, Place and Environment Commons, and the Sustainability Commons

\section{Recommended Citation}

Armsworth PR, Larson ER, Jackson ST, Sax DF, Simonin P, Blossey B, Green N, Klein ML, Lester L, Ricketts $\mathrm{TH}$, Runge MC. Are conservation organizations configured for effective adaptation to global change?. Frontiers in Ecology and the Environment. 2015 Apr;13(3):163-9.

This Article is brought to you for free and open access by the Rubenstein School of Environment and Natural Resources at UVM ScholarWorks. It has been accepted for inclusion in Rubenstein School of Environment and Natural Resources Faculty Publications by an authorized administrator of UVM ScholarWorks. For more information, please contact scholarworks@uvm.edu. 


\section{Authors}

Paul R. Armsworth, Eric R. Larson, Stephen T. Jackson, Dov F. Sax, Paul Simonin, Bernd Blossey, Nancy Green, Mary L. Klein, Liza Lester, Taylor H. Ricketts, Michael C. Runge, and M. Rebecca Shaw 


\title{
Are conservation organizations configured for effective adaptation to global change?
}

\author{
Paul R Armsworth ${ }^{1 *}$, Eric R Larson ${ }^{1}$, Stephen T Jackson ${ }^{2}$, Dov F Sax ${ }^{3}$, Paul Simonin ${ }^{4}$, Bernd Blossey ${ }^{4}$, \\ Nancy Green ${ }^{5}$, Mary L Klein ${ }^{6}$, Liza Lester ${ }^{7}$, Taylor H Ricketts ${ }^{8}$, Michael C Runge ${ }^{9}$, and M Rebecca Shaw ${ }^{10}$
}

Conservation organizations must adapt to respond to the ecological impacts of global change. Numerous changes to conservation actions (eg facilitated ecological transitions, managed relocations, or increased corridor development) have been recommended, but some institutional restructuring within organizations may also be needed. Here we discuss the capacity of conservation organizations to adapt to changing environmental conditions, focusing primarily on public agencies and nonprofits active in land protection and management in the US. After first reviewing how these organizations anticipate and detect impacts affecting target species and ecosystems, we then discuss whether they are sufficiently flexible to prepare and respond by reallocating funding, staff, or other resources. We raise new hypotheses about how the configuration of different organizations enables them to protect particular conservation targets and manage for particular biophysical changes that require coordinated management actions over different spatial and temporal scales. Finally, we provide a discussion resource to help conservation organizations assess their capacity to adapt.

Front Ecol Environ 2015; 13(3): 163-169, doi:10.1890/130352 (published online 12 Feb 2015)

$\mathbf{M}_{\mathrm{t}}$ any species and ecosystems are already responding to global environmental change, which is projected to become more rapid and extensive (IPCC 2014). Much has been written about conservation actions that could be employed in light of changing conditions. Recommendations include establishing larger protected areas, protecting or managing surrounding matrix habitats, facilitating species movements across landscapes through corridor development or managed relocation, and restoring natural disturbance regimes (Heller and Zavaleta 2009; National Fish, Wildlife, and Plants Climate Adaptation Partnership 2012; Melillo et al.

\section{In a nutshell:}

- The structure and institutional capacity of a conservation organization influences how effectively it can anticipate, prepare for, detect, and respond to changes affecting target species and ecosystems

- Conservation organizations regularly make decisions about how they are configured, and reorganization may prepare some to adapt better to changing conditions

- Institutional structure influences how well positioned a conservation organization is to protect particular targets or to manage particular threats, where coordinated actions are needed across different spatial and temporal scales

- Perceptions of the adaptive capacity of conservation organizations shift when viewed across the whole conservation sector instead of one organization at a time

${ }^{1}$ Department of Ecology $\mathcal{E}$ Evolutionary Biology, University of Tennessee, Knoxville, TN * (p.armsworth@utk.edu); ${ }^{2}$ DOI Southwest Climate Science Center, US Geological Survey, Tucson, AZ; ${ }^{3}$ Department of Ecology and Evolutionary Biology, Brown University, Providence, RI; continued on $p 169$
2014). However, a substantial disconnect exists between these recommendations and actual implementation of such measures (US GAO 2007; Archie et al. 2012). Moreover, practitioners often rule out actions, such as managed relocation and conservation triage, that dominate academic debates (Lemieux and Scott 2011; Poiani et al. 2011). In explaining why certain adaptation measures are rejected, practitioners frequently cite limited institutional frameworks, inadequate resources (financial and human), competing priorities, and a lack of information (Jantarasami et al. 2010; Archie et al. 2012).

Organizational change may be a prerequisite for any major rethinking of conservation actions. The way conservation organizations are configured often changes and we suggest that conservationists should assess choices about organizational structure no less strategically than other aspects of conservation planning. Common choices include how large a conservation organization should be (eg whether to hire new personnel, manage new properties, expand into a new area, rely on local partners to implement conservation activities, or operate an inhouse science program) and how it should be structured (eg the number, focus, autonomy, and resourcing of operating units).

Here we focus our discussion of adaptive capacity (Panel 1) primarily on public agencies and nonprofits responsible for land protection and management in the US. We consider how effectively these organizations are configured, both to anticipate and detect environmental changes that affect conservation targets (eg species or ecosystems of particular concern), and to prepare for and respond to these developments by reallocating resources. In so doing, we emphasize the importance of different spatial and temporal scales over which relevant biophysi- 
cal changes play out and of interactions between conservation organizations. We provide resources for conservation practitioners seeking to increase the adaptive capacity of their organizations (WebPanel 1) and - for researchers already well-versed in conservation planning tools and approaches - new hypotheses and empirical analyses that begin to formalize key concepts and questions. Although concentrating primarily on how organizations may achieve their current conservation objectives (incremental adaptation; Panel 1), we also recognize that in some instances rapid ecological change may require more transformational adaptation (Panel 1), which could entail a re-evaluation of an organization's mission, goals, and strategies.

\section{Anticipating and detecting changes}

Effective adaptation requires that conservation organizations project how conservation targets may be affected by global change and that any deviation in target status (either anticipated or unanticipated) can be detected. Projections and data are needed at spatial scales relevant to conservation targets and the processes affecting them, and over timescales long enough to address the directional nature of global change. They are also needed at spatial resolutions comparable to those of management actions, and with sufficient frequency to allow timely responses. This will necessitate integrating geophysical (eg climate projections, hydrology models), biological (eg

\section{Panel 1. Glossary of terms}

Adaptation - "The process of adjustment to actual or expected climate and its effects...In natural systems, human intervention may facilitate adjustment to expected climate and its effects" (IPCC 20|4)

Incremental adaptation - "Adaptation actions where the central aim is to maintain the essence and integrity of a system or process at a given scale" (IPCC 20I4)

Transformational adaptation - "Adaptation that changes the fundamental attributes of a system in response to climate and its effects" (IPCC 20I4)

Adaptive capacity - "The ability of systems, institutions, humans, and other organisms to adjust to potential damage, to take advantage of opportunities, or to respond to consequences" (IPCC 20|4)

Conservation easement - A legal arrangement under which a conservation organization acquires some rights associated with owning a particular parcel of land only (eg the right to subdivide the property or to clear-cut timber), without acquiring the full fee title

Fee simple acquisition - A land transaction in which a conservation organization acquires the title to a parcel of land and the set of property rights associated with its ownership

Managed relocation - "The intentional act of moving species, populations, or genotypes (a target) to a location outside a target's known historical distribution for the purpose of maintaining biological diversity or ecosystem functioning as an adaptation strategy for climate change" (Schwartz et al. 20I2) species vulnerability assessments), and socioeconomic (eg mitigation and adaptation responses in other sectors) information; updating model projections with new data derived from experiments and monitoring; and accounting for multiple sources of uncertainty.

Given these potential data demands, a conservation organization must consider how it will obtain the information it needs. At the very least, the organization will require relevant partnerships or adequate in-house scientific capacity to gather and interpret information on projected and ongoing changes. Moreover, it may have to seek partners to assist with or to invest directly in data analyses and synthesis, when using data in ways that make local context particularly important (eg when integrating downscaled climate projections into local conservation plans or monitoring local responses of target species to changing conditions).

Considerations of this type, where conservation organizations evaluate how best to access the information needed for effective adaptation, are complementary to ongoing dialogue within the global change and adaptation research community regarding how best to meet information demands of end-users of relevant data. Among members of the research community, this dialogue has addressed data access and integration (PCAST 2011) as well as the role of "knowledge networks" (Bidwell et al. 2013). It has also spurred development of tools and software that can help practitioners integrate global-change projections into conservation plans (eg Girvetz et al. 2009).

Conservation organizations also need to assess the effectiveness of different activities for managing impacts of global change. For an organization to learn what management approaches work best, staff must be encouraged to explore different ways of achieving conservation goals, and to report the successes and failures that result. Organizational learning of this type depends on a range of enabling factors, including external pressure for innovation and modernization, a commitment to organizational learning among supervisory staff, and a culture of openness and trust (Greiling and Halachmi 2013), all factors that vary within (Brown and Squirrell 2010) and between (Feeney and Rainey 2010; Jantarasami et al. 2010; Lemieux et al. 2013) organizations.

Of the few evaluations of organizational learning performed in conservation, the results are informative. For instance, a survey of US Forest Service staff found that the agency performed poorly against multiple metrics associated with being a "learning organization" (eg having a culture of information sharing, openness to new ideas and outside information, and a willingness to experiment) as compared with large, for-profit businesses (Garvin et al. 2008; Brown and Squirrell 2010). Such evaluations reveal areas that require improvement and opportunities for institutional growth and development that, in turn, can form the basis for effective adaptation to global change (WebPanel 1; Lemieux et al. 2013). 


\section{Preparing for and responding to change}

A conservation organization needs flexibility to reallocate resources - available funding, human resources, or other forms of capital - in order to prepare for anticipated changes or to respond to changes once detected. The organization must be able to reallocate these resources across conservation activities and across space and time on scales that are meaningful in terms of the changes it must address.

Conservation investments typically used in land protection and management vary widely in terms of their flexibility. For example, fee simple acquisitions (Panel 1) offer greater flexibility over land management than easement acquisitions, in which conservation organizations contract with landowners to secure protection only against particular threats (Rissman et al. 2015). Short-term (5-10-yr) conservation contracts, commonly used in agricultural systems, offer conservation organizations greater scope to cease investing in particular sites if these are no longer deemed as important ecologically. However, this flexibility comes with the risk that private landowners may choose not to re-enroll a property. Conservation actions that do not involve land acquisition (eg policy advocacy, education) can potentially operate with even shorter lead times and varying commitment periods.

Investments in human resources can be viewed similarly. For some conservation activities, having staff with locally specific knowledge (eg natural history or established contact networks) is important. In other cases, it is more valuable to have staff who can work effectively in diverse social and ecological systems. Another approach is to use fewer in-house staff and a greater array of partners and experts under contract, which can provide increased flexibility to adopt new strategies.
Some have argued that, along with building flexibility into their conservation investments, organizations need to revisit their underlying conservation goals (Glick et al. 2011; Stein et al. 2013). An organization focused on managing a protected area, for instance, might shift its emphasis from particular species and communities to the ecological functions these support. Alternatively, when the ranges of target species shift, the organization could modify its goals to reflect its contribution to conserving regional biota, relying on partners to take on stewardship responsibilities for species undergoing range shifts that make local conservation no longer practical.

This latter suggestion highlights an obvious limitation that many conservation organizations face: being tied to a specific geographic location. Organizations tied to fixed boundaries will struggle to respond as species move across landscapes in response to changing climatic conditions and as new areas become conservation priorities. Therefore, a common recommendation in adaptation writings is that conservation organizations should plan their activities cooperatively on a regional scale. At its most pronounced, "scaling up" could involve partnerships and even mergers among different conservation organizations. As a case in point, in 2006, eight land trusts merged to form the Western Reserve Land Conservancy (Bates 2006). More typically, scaling up entails an organization either expanding its geographic reach or collaborating with other groups on conservation planning. The national network of Landscape Conservation Cooperatives is a major ongoing effort to improve collaboration across multiple organizations for planning conservation and management activities at larger spatial scales (Panel 2). Appeals in the literature to scale up conservation planning need to consider the practicalities of multilevel governance and the advantages of having a diversity of

\section{Panel 2. Adaptation within federal agencies in the US}

US federal agencies are required to plan for climate-change adaptation under Executive Orders 135/4 (October 2009) and I3653 (November 20I3). Bierbaum et al. (20I3) reviewed progress made by these agencies ("more than before but less than needed") as well as by other sectors. They also highlight case studies where agency-led collaborations have sought to overcome barriers to adaptation.

In response to these Executive Orders, the Department of the Interior implemented two organizational changes to consolidate its approach to climate-change adaptation. First, a network of eight regional Climate Science Centers (CSCs), administered by the US Geological Survey, is now charged with synthesizing and integrating climate-change impact data and developing tools to inform resource managers (DOI Secretarial Order 3289). Second, a network of 22 Landscape Conservation Cooperatives (LCCs), administered primarily by the US Fish and Wildlife Service and organized around ecoregional boundaries, is tasked with coordinating adaptation activities across multiple stakeholder groups. These LCCs have favored decision-making processes that seek broad consensus among many partnering institutions.

The effectiveness of this reorganization will depend on several of the topics highlighted in this paper. For example, the CSC and LCC initiatives reflect an explicit drive to regionalize science and management responses to complement national-scale efforts. At the same time, the spatial domains of CSCs and LCCs are not aligned, leading to coordination challenges. Although CSCs and LCCs collaborate closely on identifying science priorities, they are usually in different locations and are administered by different agencies.

A common concern arising in discussions about the adaptive capacity of federal agencies is that their enabling statutes are too inflexible to allow adaptation and to accommodate proactive conservation measures (see Doremus [20I0] for a review of these criticisms of the US Endangered Species Act). That being said, surveys have indicated that agency staff consider some statutes (eg US National Environmental Policy Act) as more suitable for accommodating adaptation than others (Jantarasami et al. 20l0). Moreover, staff perceive adaptation opportunities as being limited more by how agencies interpret and implement legislation than by the wording of particular pieces of legislation (Jantarasami et al. 2010). 


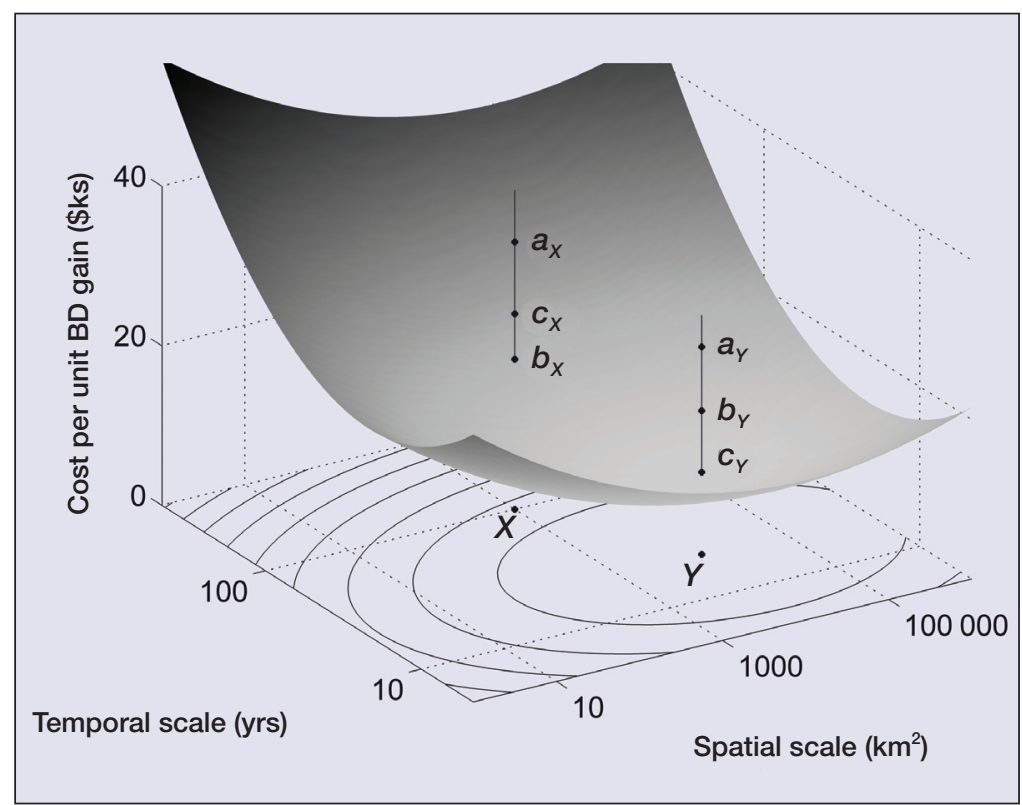

Figure 1. Cost per unit biodiversity (BD) gain in a conservation target as a function of spatial and temporal scales over which a conservation organization operates. Points X and Y illustrate two contrasting ways that an organization could be configured: conservation at a smaller spatial scale (eg a single county) over the long term ( 100 yrs) versus conservation at a larger spatial scale (several counties) in the short term (over the next few decades). With either configuration, the organization has a choice of actions (a, b, and c) that it could implement to try to protect its conservation target, and these actions vary in cost effectiveness. Moreover, which action is most cost effective depends on how the organization is configured. The gray surface represents costs per unit improvement in the biodiversity target when using the optimal action choice given the particular spatial and temporal scale over which the organization operates. $\$ k s=$ thousands of US dollars.

conservation organizations with differing goals and emphases (Berkes 2007). One useful way to frame these discussions might be to evaluate how much coordination is required, over what spatial scales, and which aspects of an organization's operations need to be involved. As an example, it may be worthwhile for organizations to collaborate more on information collection and regional target setting (Camacho 2009), while retaining individual autonomy to explore different ways of achieving conservation goals.

\section{Evaluating the effectiveness of organizational configuration}

The preceding sections described some of the considerations relevant to configuring conservation organizations for adapting to global change. We now discuss relevant hypotheses on organizational effectiveness and identify steps for conservation organizations to evaluate their current configuration.

Figure 1 illustrates a hypothesis (see also WebPanel 2) based on the relationship between the costs of achieving a unit gain for a given conservation target and the spatial and temporal scales over which a conservation organization operates, two basic descriptors of organizational con- figuration. Point $X$ might represent a local land trust working in a small county $\left(\sim 1000 \mathrm{~km}^{2}\right)$ with an operating model focused on long-term $(\sim 100-y r)$ land preservation, aimed at conserving populations of a range-restricted plant species found on some of its properties. The species is affected by a set of stressors, which operate over particular temporal and spatial scales. The organization can choose between several actions to mitigate these impacts: $(a)$ establishing a buffer zone around existing reserves, (b) performing managed relocation between reserves, or (c) enhancing the intervening matrix habitat. Using a population viability analysis (PVA), the organization estimates the costs of achieving a $2 \%$ improvement in probability of local persistence of the plant over the next 100 years with each action (height of points $a_{x}, b_{x}$, and $c_{x}$ on the vertical axis).

Current literature on adaptation focuses on identifying the most effective action with fixed organization size and structure (ie the benefit of choosing $b_{x}$ over $a_{x}$ or $c_{x}$ ). However, reconfiguring an organization so it is better positioned to work over different spatial and temporal scales may make alternative approaches more viable. In the prior example, the land trust could expand into surrounding counties and adopt more flexible investment choices (perhaps by favoring educational campaigns and short-term contracts over fee simple acquisitions), effectively relocating from point $X$ to point $Y$. The gray surface in Figure 1 represents the cost per unit improvement in the biodiversity target for an organization when performing the optimal conservation action on a certain spatial and temporal scale (ie points such as $b_{x}$, and $c_{Y}$ ). Point $Y$ represents the most cost-effective organizational configuration for achieving its conservation goal. It also implies that the most cost-effective action with the original organization configuration $\left(b_{\chi}\right)$ is not the most cost-effective one overall ( $c_{Y}$ in this example). Our focus in this paper is on efficiency gains made possible by adapting organizations to time-space-cost landscapes (ie considering all possible configurations of $a_{i}, b_{i}$, and $c_{i}$, where $i$ represents some combination of spatial and temporal scale) rather than adapting conservation actions to a fixed organizational structure (limiting an organization to point $X$ and actions like $a_{x}, b_{x}$, and $c_{x}$ ).

Implicit in the figure is a suggestion that conservation organizations need to reconsider the idea that a one-off investment in conservation today will deliver its intended conservation benefits indefinitely. Such an investment can, at best, ensure protection of conservation targets only for a finite period (Figure 1); further into the future, outcomes become less certain. Conservation organizations can extend the period over which they are confident of achieving their goals by altering investments today, but doing so will typi- 
cally cost more. For example, when establishing a protected area, a land trust will often create an endowment to fund that area's management. Establishing a larger endowment costs more initially but helps the land trust to cope better with variations in future management expenses.

To implement these concepts, an organization could first examine the approximate spatial and temporal scales over which relevant biophysical processes affecting their conservation targets occur. The use of scaling diagrams for this type of comparison is common in ecosystem ecology and biogeography (Vance and Doel 2010; Scholes et al. 2013). The spatial and temporal scales of the biophysical processes the organization seeks to influence can then be compared with the spatial extent of the organization's current conservation activities and the time frame envisioned in their current planning (horizontal axes in Figure 1; see WebPanel 2 for an example).

Estimating costs (vertical axis in Figure 1) is more difficult. While progress has been made in evaluating how conservation costs are affected by the spatial extent of conservation efforts (Armsworth 2014), few cost studies vary the time horizon over which a plan is supposed to achieve its goals (but see Busch et al. 2012; Shaw et al. 2012). Such detailed cost projections - based on PVA, conservation planning software, or similar tools - are data intensive. Yet even when data-intensive cost projections are not feasible, projections based on expert judgment may offer a way forward (Carwardine et al. 2012).

Figure 1 illustrates these cost dependencies for a particular conservation target. The position of the minimum and the steepness of the cost surface will differ depending on the choice of target. For example, the economies of scale affecting costs of conserving a particular plant community type will differ from those involved in protecting a wide-ranging vertebrate species. As such, the diversity of conservation objectives held by different organizations itself calls for a diversity of organization sizes and structures. However, if an organization is configured ineffectively for the particular targets and threats it seeks to address, then either some restructuring, or some rethinking of its goals and strategies, may be warranted.

\section{Interactions among organizations}

How effectively a conservation organization is structured to meet its objectives depends on how it interacts with and complements other such organizations. Organizations may choose to build adaptive capacity to cope only with those biophysical changes that operate over the spatial and temporal scales most relevant to their particular conservation targets (WebPanel 2). A small land trust, for instance, might respond to climate change only reactively, relying on larger entities to take a more proactive approach. Whether and when this type of risk specialization will improve conservation effectiveness will be context dependent, but again such decisions should be made strategically, in light of improved understanding of the ongoing biophysical changes affecting biodiversity.

Conservation organizations vary in size, configuration, and focal activities; from a biodiversity perspective, the collective outcome of their activities is what matters most. However, there is little reason to assume that the current distribution of organizations is well-suited to dealing with global change. Importantly, the structure of the entire conservation sector, like the structure of an individual organization, is subject to change and can be influenced by policy makers, large donors including foundations, and other key constituencies. For example, public agencies often act as essential partners to conservation nonprofits, by providing grants and collaborating on particular activities. By targeting this support, policy makers can exert considerable influence on the structure of nonprofit sectors (Eschenfelder 2011). Nonetheless, there has been little analysis or debate regarding how effectively the conservation sector is structured to deliver biodiversity outcomes under changing conditions. "Mapping" of the conservation sector in general remains rudimentary (Armsworth et al. 2012). Surveys of adaptation efforts by conservation organizations consider only the amount of related planning being undertaken (Bierbaum et al. 2013) and do not yet evaluate the efficacy of efforts that have already begun (see, for example, the case studies described in Figure 2).

We characterized the current distribution of operating models used by selected conservation organizations (USbased land trusts with a major focus on biodiversity conservation), analogous to finding the location of point $X$ in Figure 1 for each organization. On the horizontal axis of the graph in Figure 2, we plotted the area of land that these organizations manage under fee simple or easement arrangements as an indicator of the spatial extent of their operations. On the vertical axis of the graph in Figure 2, we sought to include an indicator of relative variation in the time period over which each organization could be confident of protecting conservation targets found within these areas, as for Figure 1. We assumed that an organization would be able to offset changing biophysical conditions within a given hectare for a longer time span if greater guaranteed income were available to support site management. For our indicator, we used the annual income per hectare that would be available on a sustainable basis were the organization's financial assets managed as an endowment. WebPanel 3 discusses our methodology, including sensitivity tests to alternative assumptions, in greater detail.

The operating models of these organizations vary widely. The amount of land managed varies among organizations (Figure 2), which also differ in how much secure income they have available to support management activities in these areas. Nevertheless, on average, organizations have relatively little secure income available to devote to this purpose (median investment income $=$ $\left.\$ 37.5 \mathrm{ha}^{-1} \mathrm{yr}^{-1}\right)$. Organizations managing larger areas have greater investment income overall but typically have less investment income per hectare (WebPanel 2). Indeed, as compared with large organizations, small orga- 
(a) Scenic Hudson, a large land trust with a dedicated budget for land acquisition, has taken a leadership role in climate adaptation issues by actively working to protect lands that will facilitate the migration of tidal habitats as sea levels rise. This organization recently partnered with the State of New York and with NOAA to protect a key parcel within the Hudson River National Estuarine Research Reserve, which contains critical spawning and nursery habitats for many fish species and feeding habitats for migratory waterfowl. Importantly, the land transaction protected both current freshwater tidal wetlands and areas adjacent to the inundation zone that will allow upslope migration of the wetlands under future sea-level rise.
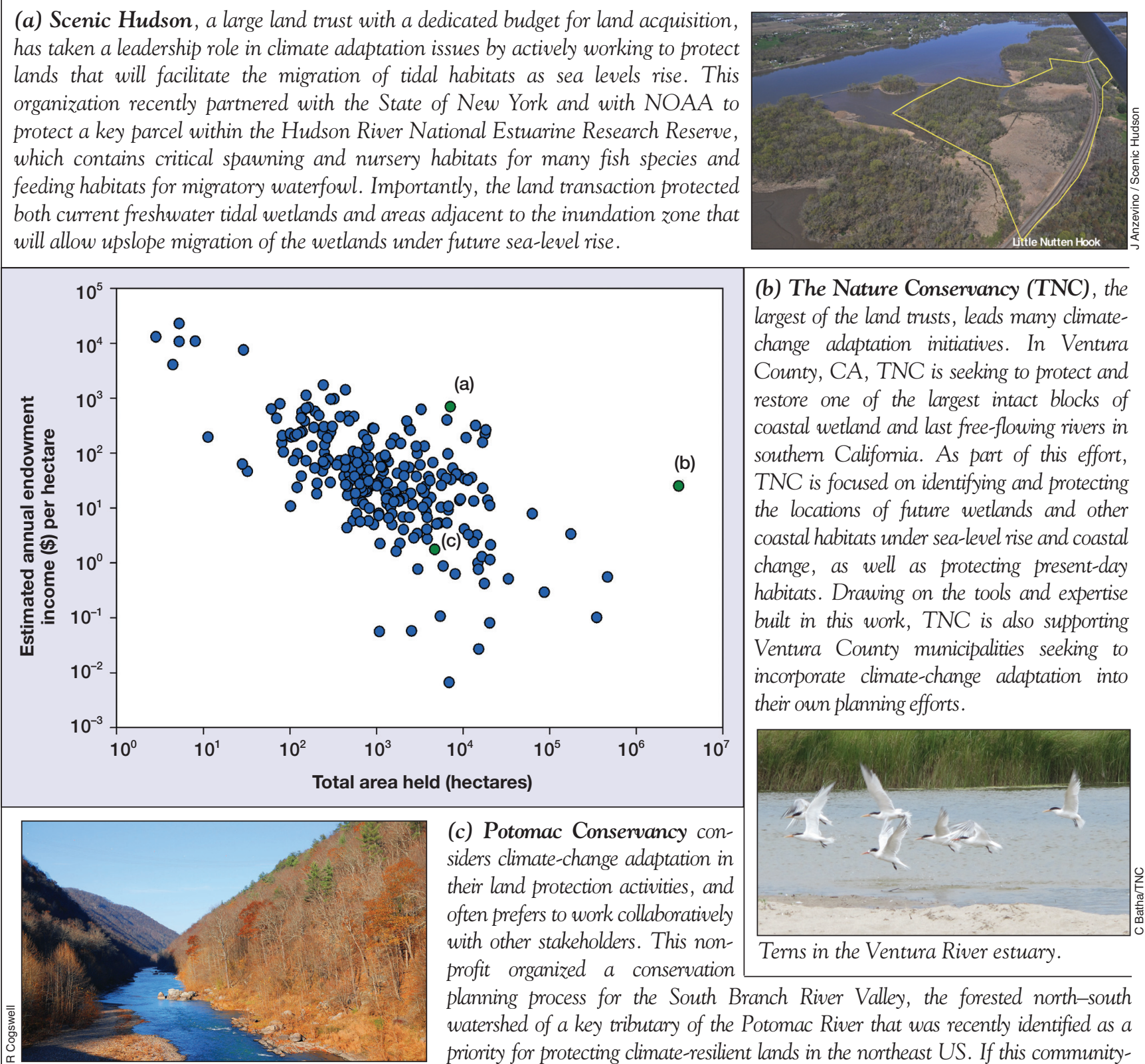

(c) Potomac Conservancy considers climate-change adaptation in their land protection activities, and often prefers to work collaboratively with other stakeholders. This nonprofit organized a conservation (b) The Nature Conservancy (TNC), the largest of the land trusts, leads many climatechange adaptation initiatives. In Ventura County, CA, TNC is seeking to protect and restore one of the largest intact blocks of coastal wetland and last free-flowing rivers in southern California. As part of this effort, TNC is focused on identifying and protecting the locations of future wetlands and other coastal habitats under sea-level rise and coastal change, as well as protecting present-day habitats. Drawing on the tools and expertise built in this work, TNC is also supporting Ventura County municipalities seeking to incorporate climate-change adaptation into their oun planning efforts.

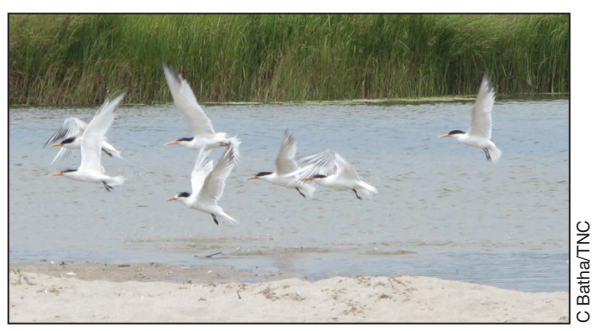

Terns in the Ventura River estuary.

planning process for the South Branch River Valley, the forested north-south watershed of a key tributary of the Potomac River that was recently identified as a priority for protecting climate-resilient lands in the northeast US. If this community"The Trough" in the South Branch of the Potomac River. driven process can successfully galvanize and coordinate protection of lands in the watershed, a large movement corridor for species will be established.

Figure 2. Variation in operating models of conservation organizations. We examined land protection practices of a sample of 245 land trusts in the US that report a major focus on biodiversity conservation. In the central graph, the horizontal axis shows the area of land managed under fee simple or easement arrangements, and the vertical axis represents annual income available per hectare on a sustainable basis from managing the organization's financial assets as an endowment. We also highlight three examples from (a) Scenic Hudson, (b) The Nature Conservancy, and (c) Potomac Conservancy as types of climate-change adaptation activities being undertaken by organizations occupying different positions in the graph.

nizations commonly have 10-1000 times the investment income available per hectare protected. At the same time, there is substantial variation in income levels, even between organizations managing similar areas and with similar conservation goals (Figure 2). Given these patterns of variation, we would expect the various organizations to differ markedly in how well-positioned they are to protect conservation targets and to respond to biophysical changes over varying spatial and temporal scales.

\section{Conclusions}

Although much attention in the scholarly literature has focused on how conservation organizations can adaptively manage target species and ecosystems in response to the impacts of global change, comparable efforts to strategically assess the structure and capacities of the organizations themselves have been limited. Are organizations within the conservation community configured, 
in terms of individual and collective institutional capacity, to adapt to global change effectively, and (if not) what can be done to improve their chances of success? The web-only materials that accompany this paper provide a resource to help conservation organizations to selfevaluate as they begin to answer this question.

\section{Acknowledgements}

We thank staff at Scenic Hudson, The Nature Conservancy, and Potomac Conservancy for assistance with the case study material in Figure 2, and G Iacona, E Lonsdorf, S Spector, and A Zepp for helpful discussions. This project was initiated at the ESA's second Emerging Issues conference, "Developing Conservation Targets under Global Change", held in February 2012. The findings and conclusions in this article are those of the authors and do not necessarily represent the views of the US Fish and Wildlife Service.

\section{References}

Archie KM, Dilling L, Milford JB, and Pampel FC. 2012. Climate change and western public lands: a survey of US federal land managers on the status of adaptation efforts. Ecol Soc 17: 20.

Armsworth PR, Fishburn IS, Davies ZG, et al. 2012. The size, concentration and growth of biodiversity conservation nonprofits. BioScience 62: 271-81.

Armsworth PR. 2014. Inclusion of costs in conservation planning depends on limited datasets and hopeful assumptions. Ann NY Acad Sci 1322: 61-76.

Bates S. 2006. Models of collaboration among land trusts. New Hampton, NH: SK Bates Conservation Consulting.

Berkes F. 2007. Community-based conservation in a globalized world. P Natl Acad Sci USA 104: 15188-93.

Bidwell D, Dietz T, and Scavia D. 2013. Fostering knowledge networks for climate adaptation. Nature Clim Change 3: 610-11.

Bierbaum R, Smith JB, Lee A, et al. 2013. A comprehensive review of climate adaptation in the United States: more than before, but less than needed. Mitig Adapt Strateg Glob Change 18: 361-406.

Brown GG and Squirrell T. 2010. Organizational learning and the fate of adaptive management in the US Forest Service. J Forest 108: 379-88.

Busch J, Dave R, Hannah L, et al. 2012. Climate change and the cost of conserving species in Madagascar. Conserv Biol 26: 408-19.

Camacho AE. 2009. Adapting governance to climate change: managing uncertainty through a learning infrastructure. Emory Law J 59: 1-78.

Carwardine J, O'Connor T, Legge S, et al. 2012. Prioritizing threat management for biodiversity conservation. Conserv Lett 5: $196-204$.

Doremus H. 2010. The Endangered Species Act: static law meets dynamic world. Washington U J Law Eु Policy 32: 175-235.

Eschenfelder B. 2011. Funder-initiated integration: partnership challenges and strategies. Nonprofit Manage Leadership 21: 273-88.

Feeney MK and Rainey HG. 2010. Personnel flexibility and red tape in public and nonprofit organizations: distinctions due to institutional and political accountability. J Publ Adm Res Theor 20: 801-26.

Garvin DA, Edmondson AC, and Gino F. 2008. Is yours a learning organization? Harvard Bus Rev 86: 109-16.

Girvetz EH, Zganjar C, Raber GT, et al. 2009. Applied climatechange analysis: the Climate Wizard tool. PLoS ONE 4: e8320.

Glick P, Chmura H, and Stein BA. 2011. Moving the conservation goalposts: a review of climate change adaptation literature.
Washington, DC: National Wildlife Federation.

Greiling D and Halachmi A. 2013. Accountability and organizational learning in the public sector. Public Performance Manage Rev 36: 380-406.

Heller NE and Zavaleta ES. 2009. Biodiversity management in the face of climate change: a review of 22 years of recommendations. Biol Conserv 142: 14-32.

IPCC (Intergovernmental Panel on Climate Change). 2014. Climate change 2014: impacts, adaptation, and vulnerability. Part A: global and sectoral aspects. Cambridge, UK: Cambridge University Press.

Jantarasami LC, Lawler JJ, and Thomas CW. 2010. Institutional barriers to climate change adaptation in US National Parks and Forests. Ecol Soc 15: 33.

Lemieux CJ and Scott DJ. 2011. Changing climate, challenging choices: identifying and evaluating climate change adaptation options for protected area management in Ontario, Canada. Environ Manage 48: 675-90.

Lemieux CJ, Thompson JL, Dawson J, and Schuster RM. 2013. Natural resource manager perceptions of agency performance on climate change. J Environ Manage 114: 178-89.

Melillo JM, Richmond T, and Yohe GW. 2014. Climate change impacts in the United States: The Third National Climate Assessment. Washington, DC: US Global Change Research Program.

National Fish, Wildlife, and Plants Climate Adaptation Partnership. 2012. National fish, wildlife and plants climate adaptation strategy. Washington, DC: Association of Fish and Wildlife Agencies, Council on Environmental Quality, Great Lakes Indian Fish and Wildlife Commission, National Oceanic and Atmospheric Administration, and US Fish and Wildlife Service.

PCAST (President's Council of Advisors on Science and Technology). 2011. Sustaining environmental capital: protecting society and the economy. Washington, DC: Executive Office of the President of the United States.

Poiani KA, Goldman RL, Hobson J, et al. 2011. Redesigning biodiversity conservation projects for climatic change: examples from the field. Biodivers Conserv 20: 185-201.

Rissman AR, Owley J, Shaw MR, and Thompson B. 2015. Adapting conservation easements to climate change. Conserv Lett 8: 68-76.

Scholes RJ, Reyers B, Biggs R, et al. 2013. Multi-scale and crossscale assessments of social-ecological systems and their ecosystem services. Curr Opin Environ Sustain 5: 16-25.

Schwartz MW, Hellmann JJ, McLachlan JM, et al. 2012. Managed relocation: integrating the scientific, regulatory and ethical challenges. BioScience 62: 732-43.

Shaw MR, Klausmeyer K, Cameron DR, et al. 2012. Economic costs of achieving current conservation goals in the future as climate changes. Conserv Biol 26: 385-96.

Stein BA, Staudt A, Cross MS, et al. 2013. Preparing for and managing change: climate adaptation for biodiversity and ecosystems. Front Ecol Environ 11: 502-10.

US GAO (US Government Accountability Office). 2007. Climate change: agencies should develop guidance for addressing the effects on federal land and water resources. Washington, DC: US GAO.

Vance TC and Doel RE. 2010. Graphical methods and Cold War scientific practice: the Stommel Diagram's intriguing journey from the physical to the biological environmental sciences. Hist Stud Nat Sci 40: 1-47.

${ }^{4}$ Department of Natural Resources, Cornell University, Ithaca, NY; ${ }^{5}$ US Fish and Wildlife Service, Arlington, VA; ${ }^{6}$ NatureServe, Arlington, VA; ${ }^{7}$ Ecological Society of America, Washington, DC; ${ }^{8}$ Gund Institute for Ecological Economics, University of Vermont, Burlington, VT; ${ }^{9}$ Patuxent Wildlife Research Center, US Geological Survey, Laurel, MD; ${ }^{10}$ Environmental Defense Fund, San Francisco, CA 


\section{WebPanel 1. Self-evaluation resource for conservation organizations}

Below, we suggest some discussion points to help a conservation organization interested in undertaking a self-assessment regarding how well-positioned it is to adapt to global change. We have assumed that each organization has already established conservation objectives and identified relevant conservation targets (eg focal populations, species, or ecosystems), and has experience implementing a particular set of conservation actions (eg acquiring land parcels as reserves, undertaking controlled burns on properties it manages, etc), in an attempt to alleviate threats affecting those targets. The information below is intended to catalyze discussions about how the organization might need to do things differently in the future. However, more general conservation planning has to come first. If the organization is starting conservation planning "from scratch", a more general conservation planning guide or resource will be of greater use (eg Margoluis and Salafsky 1998; Groves 2003; Amundsen 201 I). Sources of more general guidance regarding conservation planning in the context of climate change include Cross et al. (20I2), Groves et al. (20I2), and Stein et al. (2014).

\section{Anticipating and detecting change}

(I) Conduct an information-needs assessment. Evaluate what information will be required for the organization to be able to anticipate and detect:

(a) how threats affecting conservation targets will change or are changing;

(b) how conservation targets will be or are being affected;

(c) whether the conservation actions being deployed to prepare for or respond to climate change are effective.

With what spatial resolution (eg per parcel, county, forest block, or ecoregion) is this information needed? How frequently does it need to be updated? Evaluate the procedures, staffing, and partnerships currently in place to meet those information needs. How could these arrangements be made more effective? Also consider how relevant information is communicated both internally and to partners.

(2) Undertake a formal evaluation of different staff members' perceptions of how open the organization is to new ideas and to exploring different ways of achieving conservation goals and learning what works, and of the organization's adaptive capacity in general (see Garvin et al. [2008] and Brown and Squirrell [2010] on being a "learning organization" and Lemieux et al. [2013] on adaptive capacity in general). Dealing with rapid or unanticipated change may mean doing some things differently. This may require trying things out, learning what works well and what does not, and then sharing those lessons with others. Learning assessments of this type are designed to help evaluate how effectively an organization has fostered and maintained a culture that is conducive to this sort of learning-by-doing.

\section{Preparing for and responding to changes}

(3) Imagine a situation where a sudden change affects a conservation target of interest. For example, a new and critically important element of the biota colonizes the system for the first time; a new wildlife disease emerges, wiping out populations of key species; there is a major toxicant spill; or some type of tipping point or other abrupt change occurs. Consider the most common conservation actions used by the organization and compare the relative flexibility that each would provide in responding to this impact immediately, within the next 5 years, and within the next 10 years. Include some alternative conservation actions that are not currently being used but might be considered. What conservation actions being carried out today offer the least flexibility in terms of a response? What alternative actions would offer more flexibility while still aligning closely with the organization's overall objectives? Evaluate how effectively current staffing arrangements and current partnerships position the organization to pursue more flexible actions.

(4) Pick one of the conservation targets and work through the process described in the illustration in WebPanel 2. Specifically, estimate the relevant spatial and temporal scales over which key threats to the chosen conservation target play out. Are impacts very localized in space and time (eg runoff events, lightning strikes), thus requiring a very fine-grain response? Or are they playing out in a similar manner across the whole region? Are they moving fast (eg an emerging disease epidemic) or are they more gradual (eg increases in human population density or average temperature)? Try to sketch the contrasting scales over which different impacts play out in a figure such as that shown in WebFigure $\mathrm{I}$.

Now estimate the approximate scales over which conservation planning and conservation activities are undertaken by the organization. Do conservation objectives for the relevant target assume some time frame? Do other aspects of its conservation planning have such time frames, either explicitly or implicitly (eg "our conservation actions are really focused on the next two to three decades")? What spatial scales does planning consider, whether the conservation actions are carried out individually as an organization or through a cooperative process? What spatial scales do current conservation activities address? Try to plot the results on the figure you sketched in the previous paragraph.

What contrasts arise when the scales of conservation planning and conservation activities are drawn on the same axes as the scales of the relevant biophysical drivers? Is the organization configured to address some threats better than others? Will the organization struggle to address certain threats without relying on partners?

\section{Interactions among organizations}

(5) Repeat the broad outlines of suggested activity in section (4) above, but try to factor in what peer and partner organizations are doing. For instance, pick one of the conservation targets, and list some of the leading threats affecting that target. Evaluate which threats the organization is well-positioned to deal with, given the spatial and temporal scales over which it operates. If the organization is uniquely well-positioned to address a particular threat, how big a focus does it provide when compared to threats that peer organizations also manage well? Also evaluate which threats the organization is not as well-positioned to handle. What potential peer or partner organizations working in the same region do or can work over relevant spatial and temporal scales to address those other threats?

(6) Identify a set of peer and partner organizations and research what steps they have taken to evaluate and enhance their own capacity to deal with global change. How do they meet their information needs? What conservation actions do they favor and why? Evaluate whether the actions of and lessons learned by peers and partners open any new opportunities for the organization. Look for opportunities to share successful models for enhancing adaptive capacity and useful resources with these outside organizations (eg create a discussion board or other forum, participate in joint training activities, etc). 


\section{WebPanel 2. Additional background for Figure 1}

Figure I illustrates a hypothesis regarding how the cost of achieving a unit gain in some conservation targets depends on the spatial and temporal scales over which a conservation organization operates. These costs could be represented either by a present value sum or as an annual rate.

In the figure, the cost per unit gain is depicted as a U-shaped function of the spatial extent over which conservation activities are attempted (Armsworth et al. 20I2). Initially, conservation costs decrease with size of operations. For example, protected area management costs can show economies of scale with area (Armsworth et al. 20l I). Also, a broader spatial focus could allow an organization to adapt more flexibly to changing system dynamics, by shifting resources to areas with existing infrastructure, rather than having to make a substantial institutional change. However, once land protection programs become large enough, they reach a point where opportunities for low-cost gains have been exhausted and only more expensive opportunities remain (Withey et al. 2012). Meanwhile, transaction costs within organizations (eg breakdowns in communication, diverging incentives among staff) accumulate as organization size increases (Williamson 2005).

Figure I also suggests that the cost per unit gain will be U-shaped in time. When an organization makes an investment in conservation today, the relevant timescale is determined by how far into the future the organization projects that the investment will contribute to its conservation goals. For instance, suppose the investment is designed to conserve an endangered species and has been informed by a population viability analysis with a stated objective to ensure that the species has a $90 \%$ probability of persisting over the next $T$ years. Time horizon $T$ here would be represented on the temporal scale axis. Figure I illustrates the hypothesis that the longer the period over which an investment should continue to provide benefits, the more expensive it will be. When examining costs of conservation plans that account for climate change, Busch et al. (2012) and Shaw et al. (20I2) found evidence for this type of relationship (see Carlsson [1989] for a discussion of similar relationships in for-profit sectors). Over shorter timescales, one mechanism by which costs per unit conservation gain would decrease with time to give a $U$ shape is that revisiting a conservation plan more frequently than is necessary incurs additional transaction costs. Another mechanism would be that it takes time for conservation organizations to learn how to deliver conservation benefits in a cost-effective manner; see Jovanovic (1982) for relevant for-profit theory.

\section{Illustration}

We consider a simple hypothetical case to illustrate how a conservation organization could start to use these ideas.
Suppose a county land trust is focused on conserving local wetlands and has chosen a set of native wetland species as conservation targets, indicating progress toward this goal. Historically, the land trust had identified occasional runoff events - caused by poor stormwater management in the county containing the wetlands - as a key driver affecting these target species. The spatial scale over which these runoff events occur is bounded by the county. The relevant timescale of these impacts is determined by seasonal weather patterns and also by changing water-management practices within the county, which the land trust hopes to influence on a 5-10-year timescale (smaller shaded ellipse in WebFigure I). Suppose the land trust had configured the space and timescales of its own planning and activities to address these impacts cost-effectively and had positioned itself at point $X$ in WebFigure I. Now suppose that a recent review of threat drivers has shown that target species are also being affected by invasive species, the spread of which is associated with the gradually increasing human population density in the focal county and also in surrounding counties - a trend that is anticipated to continue for decades to come (large ellipse in WebFigure I) - as well as with other drivers such as climate change.

If the land trust were also to try to manage for this new threat, it would likely be able to do so more cost-effectively, if it expanded the spatial scale of its planning and activities into those surrounding counties and extended the timespan of its conservation planning activities to consider projected population growth in the coming decades (moving in the direction of the arrow in WebFigure I). This might be done individually, or by collaborating with relevant partners. For example, if the land trust had a regional partner also interested in conserving wetlands but specializing in preventing the spread of invasive species, then a more cost-effective strategy might be for each organization to focus on the threat to which it is best configured to respond. The idea that organizations of different sizes should specialize in differing levels of flexibility when dealing with change is well-established in publications on for-profit organizations (Mills and Schumann 1985).

Finally, if suitable partners were not available and the land trust decided that reconfiguring itself to work over larger scales was not feasible or desirable, it might instead opt to re-evaluate its choice of conservation targets. Perhaps it could emphasize the maintenance of particular wetland functions rather than focusing as much on the particular community composition supporting them, which might entail tolerating incursion by some relatively benign non-native species. 


\section{WebPanel 3. Additional background for Figure 2}

\section{Sample}

Here we provide additional details regarding the analysis shown in Figure 2, illustrating the differences between land trusts in the US reporting a focus on biodiversity conservation. To obtain our sample of 245 such organizations, we started from a larger sample of 1743 nonprofits, analyzed in Armsworth et al. (2012). This larger sample included organizations - registered as not-forprofit for tax purposes (henceforth nonprofits) in the US - that reported having a major focus on biodiversity conservation in their mission statements or descriptions of recent programs to justify their tax exempt status. The larger sample included land trusts but also many other types of conservation organization not relevant to our statistical analysis (eg advocacy groups, zoos and aquaria, etc). We filtered this larger sample to retain only those organizations that:

(a) focused on in situ conservation, as opposed to ex situ conservation (see Armsworth et al. [20I2] for details);

(b) reported their land holdings in the 2010 Land Trust Census (accessed via the Land Trust Alliance's "find a land trust database", 30 Jun 2013, http://findalandtrust.org);

(c) reported a non-zero value for land holdings and had 2010 investment income as well as assets in savings and investments (see below).

One organization in the sample (The Nature Conservancy [TNC]) is much larger than any of the others. We tested the sensitivity of the results to inclusion of this organization.

\section{Data}

For organizations' land holdings, we included both fee simple acquisitions and conservation easements (for definitions, see Panel I). We excluded areas acquired by these organizations for which stewardship responsibility had been passed to another organization (sometimes referred to as "take-outs", "transfers", or "assists"). We repeated our analyses using two other measurements of area to check for any sensitivity of our conclusions. Specifically, we repeated our analyses using (I) only the area held by these organizations under a fee simple arrangement and excluding easements and (2) a proxy measure for "service area" that multiplied the counties that each land trust was active in (according to the Land Trust Census) by the areal extent of each county. All three metrics were correlated with one another. Moreover, the conclusions that we draw from our analyses in the main text were not affected by the metric used. Therefore, we only report the results for the case with fee simple and easement area combined.

To align with the schematic shown in Figure I, ideally we would also measure timescales over which these organizations could ensure their conservation objectives would be met on sites for which they had stewardship responsibilities, given uncertain future conditions. No direct measurement of this type is available. Instead, to illustrate the relatively simple points highlighted by Figure 2 (eg that there is a diversity of organizations configured to work over contrasting spatial and temporal scales), we sought to construct a proxy that might be expected to capture some of the relative variation between organizations. Specifically, we assumed that an organization with greater guaranteed income per hectare from returns on savings and financial assets (ie income that is relatively independent of annual variation in donations or fundraising successes) would be better positioned to manage protected areas in line with its conservation goals under future changes. We obtained asset data as combined savings and investments and also as recent income from investments, by examining organizations' Internal Revenue Service form 990 tax return records, which we accessed through Guidestar (www.guidestar.org). We used tax returns from the year 2010 to match the year reported in the Land Trust Census data.

We faced a choice regarding how to characterize an organization's secure income from tax returns. In the main text, we consider the case where the organizations manage their combined savings and investments (dividends, interest, etc) as long-term endowments and show results for the case where $4 \%$ of spending was permitted against the endowment principal. To test the sensitivity of our results, we also repeated our analyses using actual reported investment income for the 2010 fiscal year for each organization.

\section{Analysis and results}

Organizations managing larger areas of land have greater investment income available, whether measured as 2010 investment income (Spearman's rho $=0.279, P<0.001, n=245$ ) or as potential income from managing combined 2010 savings and investment assets as an endowment (Spearman's rho $=0.278$, $P<0.00 I, n=245$ ). Moreover, relationships between land area held and this secure income (whether as 2010 investment income or $4 \%$ returns on 2010 savings and investments) appear linear after log-transformation (WebFigure 2); these results are not sensitive to excluding one outlier (The Nature Conservancy).

Importantly, however, the slopes of best-fit lines were significantly less than I (all $P<0.001$ ). This implies that organizations managing more land have less income per hectare available than those managing only small areas. In Figure 2, we highlight this relationship between area and income per hectare to align more closely with the schematic shown in Figure I, which focuses on a unit of conservation improvement. But for the purposes of statistical analyses, we have chosen to analyze the relationship between our income measure and area directly, rather than between income per unit area and area, to avoid any concerns about spurious correlation (Brett 2004). 


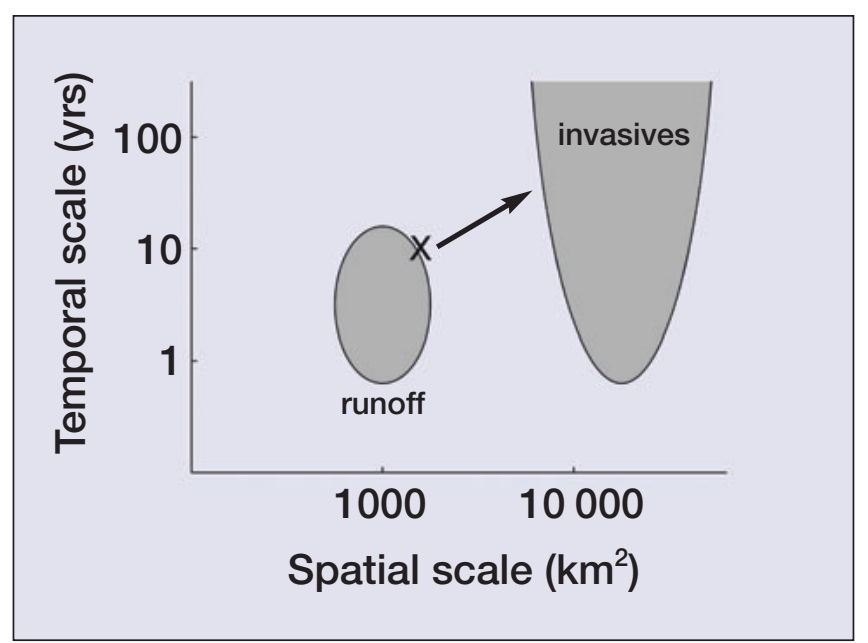

WebFigure 1. Schematic illustrating how a scaling diagram can be used to compare the space and timescales over which a conservation organization currently operates (point $X$ ) with the space and timescales of threats affecting its chosen conservation targets (small ellipse: poor stormwater management within a county; large ellipse: spread of invasive species associated with gradual development in surrounding counties). The arrow indicates a potential direction that reorganization or partnering might favor.

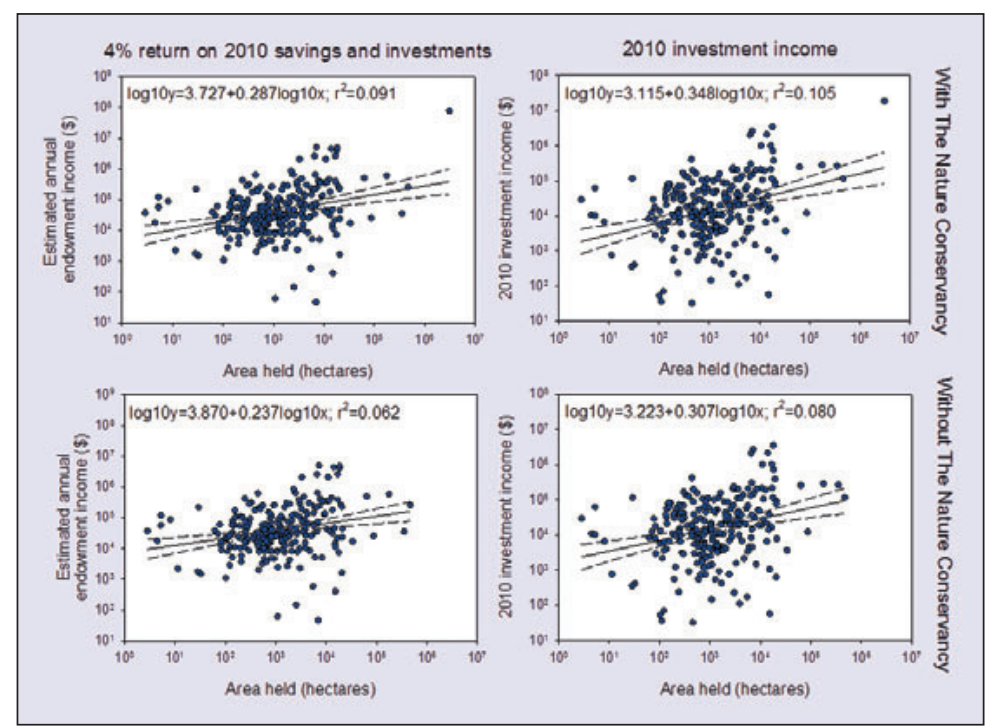

WebFigure 2. The area of land managed under either fee simple or easement arrangements for each organization is plotted on the horizontal axis. The investment income available to each organization is plotted on the vertical axis, with both sets of axes presented on a logarithmic scale. The top left panel is based on the same data as shown in Figure 2 but is provided here in terms of investment income itself instead of investment income per hectare. The next three panels provide sensitivity tests, using either 2010 investment income rather than a 4\% return on 2010 savings and investments, and/or excluding a single large outlier (The Nature Conservancy) for both measures of secure income. 


\section{WebReferences}

Amundsen OM III. 2011. Strategic conservation planning. Washington, DC: Land Trust Alliance.

Armsworth PR, Cantu-Salazar L, Parnell M, et al. 2011. Management costs for small protected areas and economies of scale in habitat conservation. Biol Conserv 144: 423-29.

Armsworth PR, Fishburn IS, Davies ZG, et al. 2012. The size, concentration and growth of biodiversity conservation nonprofits. BioScience 62: 271-81.

Brett MT. 2004. When is a correlation between non-independent variables "spurious"? Oikos 105: 647-56.

Brown GG and Squirrell T. 2010. Organizational learning and the fate of adaptive management in the US Forest Service. $J$ Forest 108: 379-88.

Busch J, Dave R, Hannah L, et al. 2012. Climate change and the cost of conserving species in Madagascar. Conserv Biol 26: 408-19.

Carlsson B. 1989. Flexibility and the theory of the firm. International J Ind Organ 7: 179-203.

Cross MS, Zavaleta ES, Bachelet D, et al. 2012. The adaptation for conservation targets (ACT) framework: a tool for incorporating climate change into natural resource management. Environ Manage 50: 341-51.

Garvin DA, Edmondson AC, and Gino F. 2008. Is yours a learning organization? Harvard Bus Rev 86: 109-16.

Groves C. 2003. Drafting a conservation blueprint: a practi- tioner's guide to planning for biodiversity. Washington, DC: Island Press.

Groves CR, Game ET, Anderson MG, et al. 2012. Incorporating climate change into systematic conservation planning. Biodivers Conserv 21: 1651-71.

Jovanovic B. 1982. Selection and evolution of the industry. Econometrica 50: 649-70.

Lemieux CJ, Thompson JL, Dawson J, and Schuster RM. 2013. Natural resource manager perceptions of agency performance on climate change. J Environ Manage 114: 178-89.

Margoluis RA and Salafsky N. 1998. Measures of success: designing, managing and monitoring conservation and development projects. Washington, DC: Island Press.

Mills DE and Schumann L. 1985. Industry structure with fluctuating demand. Amer Econ Rev 75: 758-67.

Shaw MR, Klausmeyer K, Cameron DR, et al. 2012. Economic costs of achieving current conservation goals in the future as climate changes. Conserv Biol 26: 385-96.

Stein BA, Glick P, Edelson N, and Staudt A. 2014. Climatesmart conservation: putting adaptation principles into practice. Washington, DC: National Wildlife Federation.

Williamson OE. 2005. The economics of governance. Am Econ Rev 95: 1-18.

Withey JC, Lawler JJ, Polasky S, et al. 2012. Maximising return on conservation investment in the conterminous USA. Ecol Lett 15: 1249-56. 